ББК 76.100 .5

\title{
O.P. XPOMOB
}

\section{СТРУКТУРА КНИЖНОЙ КУЛЬТУРЫ НОВОГО ВРЕМЕНИ И МЕХАНИЗМЫ ИСТОРИЧЕСКОГО РАЗВИТИЯ КНИГИ}

\section{Олег Ростиславович Хромов,}

Московский государственный академический художественный институт им. В.И. Сурикова при Российской академии художеств,

проректор по научной работе

Товарищеский пер., д. 30, Москва, 109004, Россия

Российская государственная библиотека,

Центр по исследованию проблем развития библиотек в информационном обществе,

сектор изучения особо ценных фондов,

главный научный сотрудник

Воздвиженка, д. 3/5, Москва, 119019, Россия

доктор искусствоведения, действительный член (академик) Российской академии художеств

E-mail: oleghrom@gmail.com

Реферат. Статья посвящена изучению формы книги и книжной культуры эпохи Нового времени. Форма книги определяется автором в прямой зависимости от техники книги, ее художественного образа, а книжная культура эпохи рассматривается как совокупность различных форм книги в их взаимодействии. Автор реконструирует книжную культуру эпохи на основе ключевых техник книги: рукописи, гравюры, типографской печати, которые определяют существование трех базовых форм книги эпохи Нового времени: рукописной, типографской, цельногравированной. Каждая из этих форм, по мнению автора, определена конкретными общественными потребностями и запросами эпохи. Помимо трех основных форм в книжной культуре Нового времени существуют гибридные формы книги, появившиеся в результате взаимодействия различных техник книги: «полугравированные-полурукописные», «гравировано-типографские» $и$ m. $n$. Их возникновение обусловлено общественными потребностями и тех- ническими возможностями эпохи. Соотношение техник книги в конкретную эпоху зависит от уровня развития системы книгораспространения.

При подобном подходе история книги рассматривается как последовательная смена типов книжной культуры, которая происходит в связи с появлением новых техник книги. Появление новых техник книги постепенно выводит из стабильного состояния устойчивый (традиционный) тип книжной культуры в силу появления в его недрах новых форм книги $u$, таким образом, способствует появлению нового типа книжной культуры и нового периода в развитии книги, ее истории. Подобный подход, модель развития книги показаны впервые.

Ключевые слова: книговедение, гравюроведение, гравюра, история книги, искусство книги, рукописная книга, цельногравированная книга, типографская книга, книгопечатание.

Для цитирования: Хромов О.Р. Структура книжной культуры Нового времени и механизмы исторического развития книги // Обсерватория культуры. 2017. Т. 14, № 3. С. 344-357.

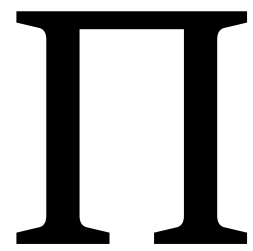

онятие «книжная культура» существует практически изначально в науке о книге и литературе. Сегодня написаны серьезные теоретические исследования об определении и наполнении понятия «книжная культура», принципах его изменения и т. п. [1-8]. Однако несмотря на серьезные монографические исследования, это понятие по сей день не обрело общепринятой дефиниции. В основном в гуманитарных науках под книжной культурой понимают явления, связанные с созданием и бытованием, включая книгораспространение, книги. В работах, 
более близких к литературоведческой, историконаучной тематике, в понимание книжной культуры включают содержание книги и его влияние на различные сферы человеческой деятельности.

Несмотря на то что в истории книги, книговедении существуют другие идентичные «книжной культуре» обобщающие понятия, такие как «книжность», «книжное дело» и т. п., отличающиеся семантическими деталями, именно понятие «книжная культура» наиболее часто применяется исследователями для определения особенностей конкретной эпохи. Это не случайно, ибо из всех применяемых в истории книги понятий «книжная культура» представляет наиболее универсальное и в то же время позволяющее говорить об особенностях явлений конкретной эпохи.

Главное в понимании книжной культуры эпохи, на наш взгляд, - наполнение самого понятия, отражение в нем конкретных исторических событий, связанных исключительно с книгой, изменением ее формы, внешности, что позволяет рассматривать историю книги как процесс смены явлений, изменений, открывающих новую эпоху в истории книги и новый тип книжной культуры. Замечу, что под формой книги я понимаю физическую форму книги как особую художественную конструкцию (единый ансамбль элементов: декоративных и конструктивных), существующую в пространстве, как особый феномен культуры.

Важной задачей становится выяснение хронологических периодов книжной культуры. Сегодня в истории книги вопросы, связанные с определением хронологических периодов, остаются открытыми в силу ряда обстоятельств. Во-первых, отсутствие единых критериев в определении значимых этапов развития книги, во-вторых, попыткой замены определения «внутренних» (т. е. собственно развития формы книги) этапов в истории развития книги на общеисторические (государственные, политические и т. п.) и подчинение им исторического пути книги, в-третьих, обращение в определении этапов исторического развития книги не к внутреннему развитию книги, а к внешним, связанным с содержанием, общественным служением книги и т. п. Можно еще перечислить ряд методов определения и периодизации исторических этапов развития книги, но в целом их можно свести к двум основным направлениям. Первое - определение этапов, исходя из «внутреннего» развития книги, второе - из «внешних» обстоятельств, включая содержание и роль книги в обществе.

В настоящее время в литературе предпочтение отдается второму направлению. Причина тому в характере отечественных историко-книговедческих исследований, связанных, прежде всего, с изучением истории издательств и конкретных изданий, взаимосвязям писателя - издателя - читателя, изучением книгораспространения, истории иллюстрирования (как работы художника) и т. п., но не самой формы книги, ее истории и изменения во времени, технике, влиянии на известные формы книги различных внешних исторических факторов.

В начале XX в. в первых исследованиях, посвященных изучению книги, уже была ясно обозначена мысль об изучении формы книги. Об особой науке о «внешности» книги писал в своих работах в 1920-х гг. А.А. Сидоров [9; 10]. Само понимание книги как особой формы, явления пространственных искусств было определено на заседаниях Полиграфической секции Государственной академии художественных наук. Именно в работе этой секции, а также на заседаниях Русского общества друзей книги складывалась особая методика изучения книги как особого явления художественной культуры и ремесла, феномена в культуре человеческого общества. К сожалению, большая часть теоретического наследия той эпохи осталась в архивах ${ }^{1}$, в протоколах заседаний, стенограммах выступлений и не получила систематических публикаций [11-13]. Тем не менее, методологические принципы, заложенные в этих исследованиях, представляют огромное значение, особенно в наши дни, когда изучение внешней истории книги (истории издательств и издателей, взаимоотношение авторов и издателей, книжной торговли и т. п.) достигло больших результатов, позволяющих по-новому посмотреть на историю развития, эволюцию формы, искусство книги.

Рассматривая книгу как особый феномен, организующий и сплачивающий вокруг себя особое пространство книжной культуры, мне представляется более продуктивным подход в определении хронологии истории книги, основанный на историческом изучении ее формы в окружающей среде книжной культуры. При этом важно понимать стимулы, влияющие как на развитие формы книги, так и ее изменение и разрушение. Очевидно, что они скрываются в окружающем книгу пространстве книжной культуры, внешней истории книги.

Форма книги (материальная форма книги) важнейшее понятие в ее истории. Внешние, материальные, художественные особенности книги говорят о вкусах эпохи. Ее конструктивные качества - о технике книги, способах ее изготовления, прогрессе в книжном деле.

Форма книги, с одной стороны, продукт материального труда, связанный с ее техническим воплощением, с другой стороны, она неизбежно зависит и определяется эстетическим вкусом, ее художественным пониманием как идеальным воплощением мысли мастера книги. Форма книги зависит от цели, задач, стоящих перед мастером, или той сто-

${ }^{1}$ См., например: Российский государственный архив литературы и искусства (РГАЛИ), ф. 941, оп. 9. 
роны книжной культуры, которая особенно востребована в обществе, что может найти отражение не только в художественном образе книги, но и ее тираже и т. п. Важным методологическим принципом в изучении истории развития формы книги является понимание и изучение структуры книжности эпохи с точки зрения техники книги, поскольку эволюция формы книги и ее многообразие в конкретную эпоху неизбежно связаны с техническими возможностями эпохи.

Итак, форма книги как материальное воплощение текста (информации), может или позволяет говорить о структуре книжной культуры как отражении развития книги в конкретную эпоху. Изменения в форме книги изменяют структуру книжной культуры и открывают новый этап в истории книги. При этом под структурой книжной культуры, ее наполнением мы понимаем многообразие и взаимодействие различных форм книги в конкретную эпоху. Их стабильное состояние показывает устойчивый тип и конкретный этап исторического развития, изменения в формах указывают на переходные периоды, развитие нового исторического этапа истории книги.

При таком подходе невозможны прямолинейные схемы, например, господствующее в литературе понимание книжной культуры России Нового времени как эпохи господства и победы типографской книги, гражданской печати и т. п. Изучение книги XVIII в., создание сводных каталогов по регионам показало, сколь многообразны жанры книжной продукции, бытовавшие в России XVII-XIX вв., в равных правах находилась книга типографская гражданская и кириллическая, цельногравированная и рукописная [14-17]. Эти различные формы книги (по способу ее изготовления) находились в тесной взаимосвязи, каждая из которых соответствовала и отвечала, была обусловлена своим существованием конкретным запросам общества.

При всем многообразии эти формы книги по способу изготовления относились к одному типу ручному производству. Несмотря на применение типографского или гравировального (фигурного) стана, книга все равно создавалась вручную, ручным трудом наборщика, художника, гравера, печатника и др. Применение ручного (не машинного) труда определяло индивидуальность экземпляра, придавало живой, рукотворный характер книге, особо ценимый сегодня библиофилами. Ручной способ изготовления книги неизбежно порождал развитие вариантов тиражей, набора, издания, а также экземплярных особенностей.

Очевидно, что книги, созданные по одной большой (ручной) рукотворной технологии, даже при различных конкретных способах изготовления техниках книги, подчинялись в целом одним зако- нам развития, изменения и взаимодействия формы книги и исторической жизни. С этой точки зрения можно говорить о книжной культуре Нового времени или эпохи ручного производства книги как о совокупности взаимодействий различных форм книги по способу изготовления: рукописной, цельногравированной и типографской.

При таком подходе структура книжной культуры Нового времени может рассматриваться как взаимодействие нескольких способов изготовления книги (техник книги) и соответственно различных форм книги, что позволяет увидеть не только все многообразие книжной культуры, но и взаимодействие различных форм книги как исторически неизбежного явления, результаты этого взаимодействия и рождения новых форм книги. Собственно история книги при таком подходе будет представлять собой историю рождения, развития и исчезновения или перехода в новую структуру книжной культуры или, шире, художественной культуры формы книги.

Форма книги - не случайное явление и обусловлена не только техническими возможностями общества, но и его конкретными потребностями в передаче и распространении информации. Наиболее древний или архаический способ изготовления книги, продолжающий свое существование в эпоху Нового времени, - рукописный. Эта техника книги олицетворяет собой предшествующий эпохе Нового времени тип книжной культуры, который всеобъемлюще можно определить как рукописный.

В эпоху Нового времени в России данный способ представлял собой неизбежное наследие прошлого, что было обусловлено в основном потребностями общества и в меньшей степени его техническими возможностями.

Рукописная книга по способу изготовления могла отображать информацию любого типа, будь то трудный или традиционный текст, написанный на разных языках со сложными изобразительными или декоративными элементами. По сути, для рукописного способа нет никаких ограничений в создании художественного образа книги.

Единственный недостаток рукописного способа - отсутствие тиража, уникальность книги. Именно борьба с этим ограничением привела к постепенному нарушению стабильности в рукописном типе книжной культуры, появлению в ее недрах элементов новых техник книги. В России первоначально это проявилось в создании книжного декора, иллюстраций посредством применения трафаретов, иконописных техник (отлепа или так называемой плоской печати и др.), использования различных технологий переписывания книги в скрипториях (этот путь известен преимущественно в Европе).

Появление книгопечатания, деятельность Ивана Федорова и первопечатников также первона- 
чально практически не повлияли на изменение формы книги. Она как нечто новое дополнила репертуар, но не изменила типа книжной культуры. Существуя несколько изолированно, даже вызывала недоверие, но постепенно органично слилась с рукописной книгой в едином пространстве книжной культуры. Однако для России на протяжении XVI-XVII вв. рукописный способ изготовления книг оставался основным. Типографская печать не коснулась всех сторон репертуара. Она заняла свою нишу в нем, но не вытеснила рукописного производства книг, не изменила типа книжной культуры в XVI и большей части XVII века. Понадобилось несколько десятков лет, чтобы новое изобретение стало постепенно изменять тип и структуру книжной культуры. Хорошо известно, что первоначально типографская книга ориентировалась на рукопись, позднее рукописная книга стала повторять сложившуюся систему оформления типографской книги, но эти изменения коснулись лишь художественной формы, а не технологии изготовления основного репертуара русской книги, которая попрежнему оставалась рукописной.

По настоящему изменение формы рукописной книги в России началось не с появления типографской печати, а с появления в рукописной книге инородных тиражных техник гравюры: ксилографии и гравюры на металле, которые изменяли не только оформление книги, но и ее изготовление. С этого момента в рукописной книге начинается разрушение традиционного типа книжной культуры (рукописной) и рождение нового типа [18; 19].

Начало этого процесса проявляется в Европе в XV в., в России в XVII в., когда в органическое тело рукописного типа книжной культуры проникают механические приемы, связанные с применением инструментов, специальных станов для получения тиража украшений, текстов и тому подобных элементов традиционной книги. Их появление воспринимается как нечто чужеродное для рукописи, но именно эти сторонние элементы, развиваясь, уничтожали традицию, открывали новые страницы в истории книги.

Постепенно в рукописи проникали печатные заставки, концовки, орнаментальные наборные украшения, которые мастера книги старательно заимствовали из печатных изданий, макулатурных листов (пробных оттисков Московского печатного двора), изъятых из типографий, и создавали из них изящные коллажи, своеобразные индивидуальные экземпляры книг, обладающие уже иной эстетической ценностью и значимостью для московских книжников ${ }^{2}$.

В литературе уже писалось о том, что гравюра в рукописной книге появилась отнюдь не исклю-

${ }^{2}$ Применение ксилографии в русской рукописной книге рассмотрено, например, в нашей публикации [20].

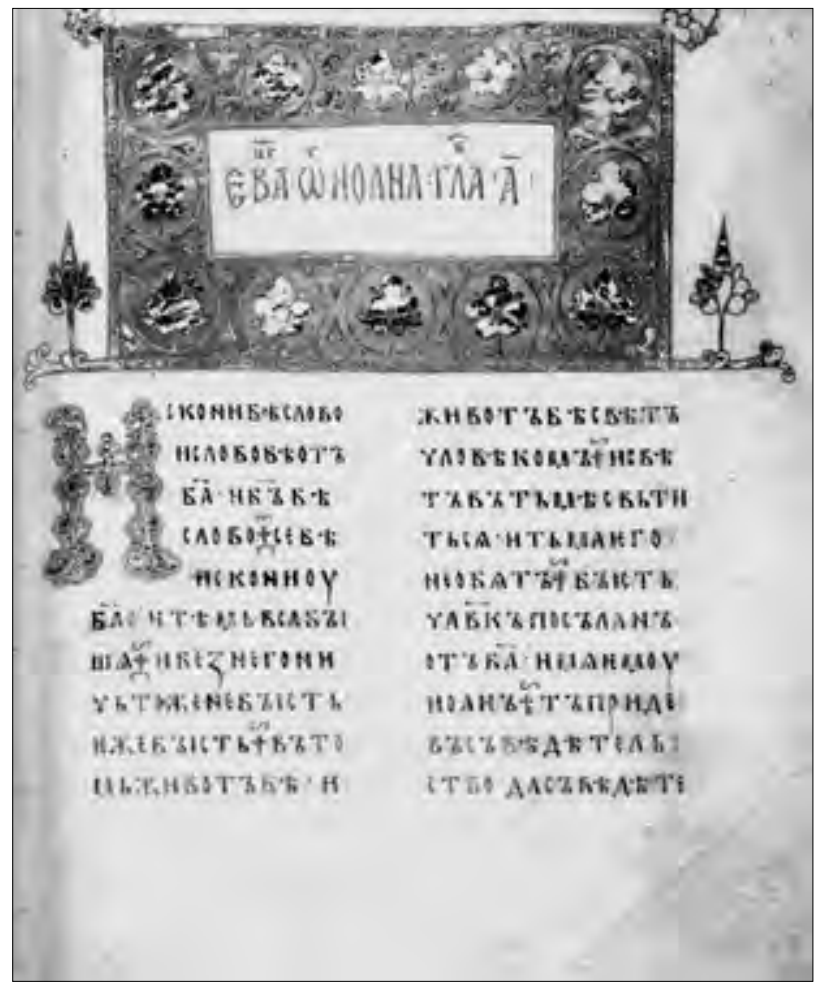

Рукопись. Остромирово Евангелие. Лист 2. Сер. XI века. Российская национальная библиотека

чительно в силу отсутствия хороших миниатюристов, а совершенно по иным причинам, связанным с появлением новой эстетики, новым пониманием художественной ценности и красоты книги, ее оформления. В последней трети XVII в. в России появляются мастера, которые профессионально занимаются созданием книг с гравюрами, гравированными коллажами, причем их заказчиками становятся представители интеллектуальной элиты общества, аристократия [21-28].

В полной мере новое оформление книги нашло воплощение в рукописях последней четверти XVII в., когда гравированные украшения (рамки-заставки, иллюстрации, заставки, концовки, полевые украшения), выполненные в техниках гравюры на металле (в основном, резец или офорт и резец) и дереве стали осуществлять функции своеобразного художественного каркаса (макета) рукописной книги, полностью определять ее художественную форму, даже при наличии изящно рисованных инициалов, буквиц и т. п. Рукописный текст и элементы художественного оформления органически вписывались и сочетались с гравированными элементами, доминировавшими в художественном облике книги, определяли ее художественную форму и внешность. Формирование этого типа книг (полурукописных, полугравированных) оформилось в 1680-1690-х годах. Такие книги по своим художественным особенностям можно отнести к особому жанру рукописной книги - 


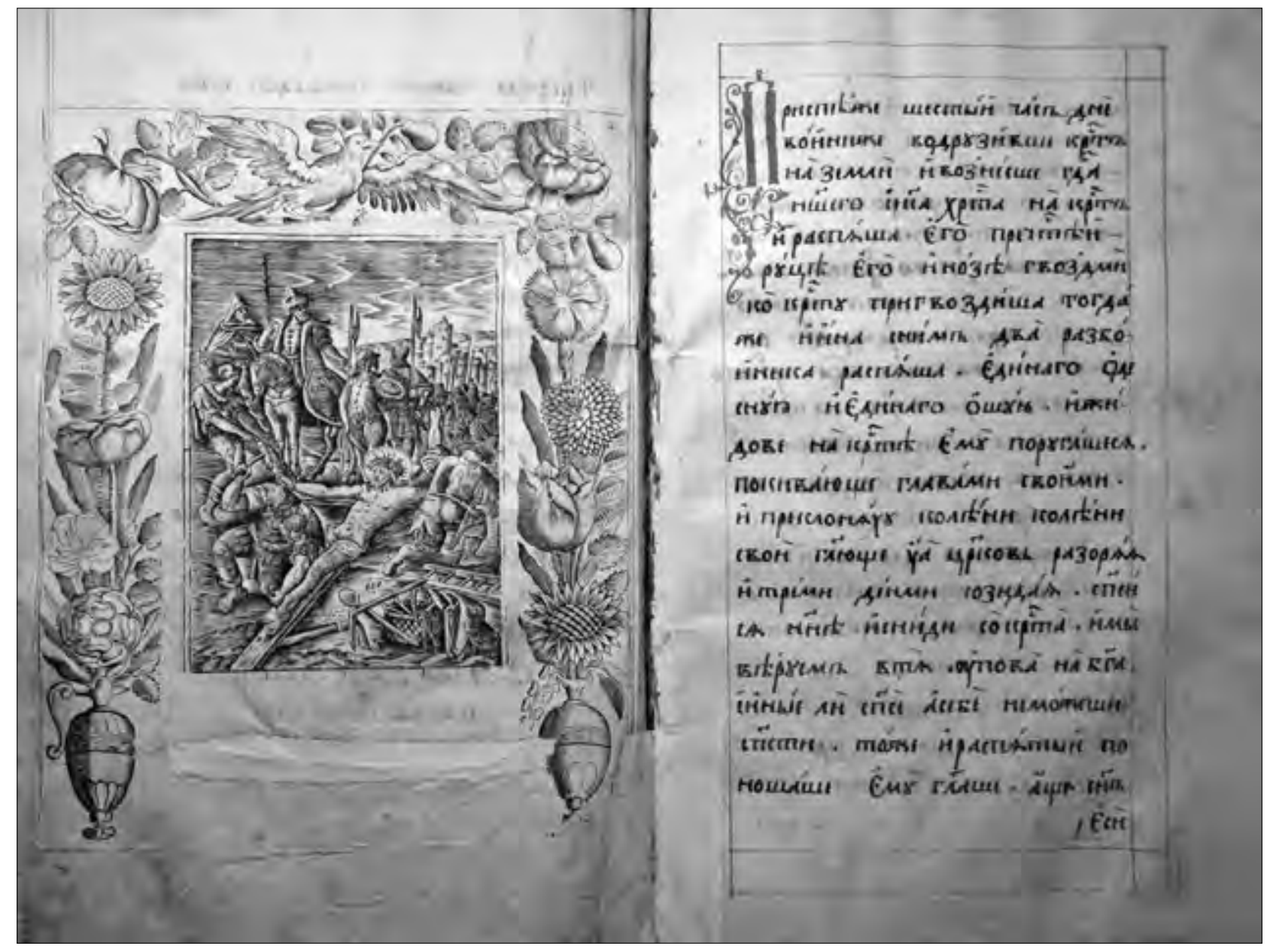

Рукопись с гравюрами.

Разворот книги «Страсти Христовы» с гравированной иллюстрацией Леонтия Бунина «Снятие с Креста» из 14-листовой серии и гравированной рамкой Асранасия Трухменского (лист из серии «Времена года», рамка «Осень»). 1691 г. Ярославский историко-архитектурный и художественный музей-заповедник (ЯМЗ. № 54403/3)

рукописи с гравюрами. Этот жанр продолжал развиваться и в последующие столетия [29-31].

Уже в XVII - начале XVIII в. в этом жанре выделились книги определенного содержания: певческие («Октоих», «Праздники» и др.), украшенные, в основном, гравированными на меди рамками-заставками, «Страсти Христовы» с различными сериями гравированных иллюстраций (Леонтия Бунина 22- и 14-листовых, Мартина Нехорошевского и др.), «Апокалипсис», «Синодик» (оба с несколькими вариантами серий гравированных иллюстраций) и др. Эти книги, в которых иллюстрации и декор выполнены в технике гравюры на меди, имеют относительно устойчивый состав и содержание и могут в прямом смысле быть отнесены к жанру гравюр с рукописями к полугравированным-полурукописным книгам. Их первые образцы относятся к XVII веку. Это «Святцы Антониево-Сийского монастыря» (ок. 1670), «Синодик» с гравюрами на дереве (1680-е), «Синодик» Леонтия Бунина (ок. 1700), «Страсти Христовы» с 14-листовой серией гравюр Леонтия Бунина (1680-е) и др. [28; 32-37].

Формирование жанра рукописной книги с гравюрами происходит в XVII в. и связано с первыми опытами их применения в своеобразном совмещении новой техники с традиционным рукописным способом изготовления книги. Уже в 1660-1670-х гг. наблюдаются первые опыты сознательного использования гравированных и печатных украшений в рукописной книге, когда мастер (художник, автор) книги умышленно отказывается от применения традиционного способа создания книги и обращается к новой технике, обладающей в его понимании особой, значимой для него художественной образностью, эстетикой.

B XVII в. появляются особые листовые издания Московского печатного двора, представляющие собой листы (в пол-листа) с отпечатанными на них орнаментальными ксилографиями заставок, концовок, элементами полевого украшения и наборны- 
ми декоративными бордюрами, предназначенными для украшения рукописных книг [20; 38]. Фактически одновременно с изданиями Московского печатного двора появляются отдельные гравированные рамки-заставки московских граверов и художников: Симона Ушакова, Афанасия Трухменского, Василия Андреева, Леонтия Бунина [39-43]. Комплекты этих гравированных на меди украшений определили окончательное рождение нового жанра в традиционной книжной культуре - рукописной книги с гравюрами и одновременно зарождение нового типа книжной культуры, в котором гравюра стала занимать равноправное положение с другими техниками книги.

Однако рукописный (архаический) способ создания книги продолжает оставаться в чистом виде в русской книжной культуре Нового времени при развитом книгопечатании. Причина этого явления кроется в самой культурной ситуации, сложившейся в России XVII-XIX веков. Рассматривая рукописную книгу Нового времени, мы видим не только старообрядческое книгописание, обласканное вниманием исследователей и обусловленное узкоконфессиональными принципами, но и светскую рукописную книгу и, конечно, духовную книгу, не относящуюся к старообрядчеству. Среди светских и духовных рукописных книг встречается значительное число списков с печатных изданий. Причины их широкого распространения во многом объясняет система книгораспространения, существовавшая в России XVII-XIX веков. Заметим, что по мере развития системы книгораспространения рукописная книга постепенно сокращала свое пространство, вытеснялась типографской, копирование которой теряло смысл. Конечно, нельзя забывать в этом процессе и о роли совершенствования производства бумаги, ее удешевлении, что сделало типографскую книгу более рентабельной и доступной к XIX веку.

Книгораспространение связывает непосредственное производство книги и ее читателя, зрителя, конкретного человека, которому она адресована. Именно от степени развития способов книгораспространения зависит во многом и наличие тех или иных форм книги и техники ее изготовления. Это важный фактор развития книжной культуры, процесс без которого нет полноценной жизни книги. Степень развития системы книгораспространения во многом определяет структуру книжной культуры, сохранение архаических или стремительное развитие новых техник книги. Отсутствие такой системы может замедлить прогрессивное высокотиражное производство книги и, напротив, сохранить архаические техники, старые, традиционные формы книги, переход которых в новое качество художественной культуры тесно связан с развитием системы книгораспространения.
Не только система книгораспространения обеспечивала сохранение рукописной книги в эпоху Нового времени. Существование некоторых ее жанров было обусловлено уровнем развития техники книги, например, для объемных нотных богослужебных книг. Их издание типографским способом было крайне сложно технически, выпуск их в цельногравированной форме вызывал серьезные материальные затраты, наиболее оптимальной техникой их производства оказывался рукописный способ.

В этом отношении можно говорить о двух главных факторах развития книжной культуры: техника книги и система книгораспространения. Техника определяет существование многообразия форм книги, книгораспространение во многом регулирует их соотношение.

Изобретение гравюры в истории книги сыграло не меньшую роль, чем изобретение книгопечатания И. Гутенбергом. Типографская печать и гравюра на многие столетия оставались главными способами создания тиражной книги и распространения и передачи информации. Эти две техники создания книги дополняли друг друга и без их взаимодействия невозможно представить себе развитие книжной культуры в эпоху Нового времени.

Типографская печать (высокая печать) была идеальным и самым совершенным способом тиражирования текстов, но для распространения иллюстраций, тиражирования изобразительных материалов изобретение И. Гутенберга было бессильно. Единственным способом репродуцирования и распространения изображений на многие столетия оставалась гравюра. Как техника книги она тесно взаимодействовала с типографской печатью, без гравюры трудно представить книгу XVI-XIX веков. Эта техника, преимущественно ксилография, применялась при создании книжного декора (заставок, концовок, виньеток, рамок, инициалов и пр.), она оказалась незаменимой и для тиражирования иллюстраций [44].

Гравюра создавала не только художественный облик книги, но и оказывалась незаменимой техникой научной книги. Только техника гравюры (гравюры на меди, офорта, как более пластичная нежели ксилография, приближающаяся по точности передачи изображения к собственно рисунку) позволяла исполнить и напечатать технические, архитектурные, фортификационные и другие чертежи и вместе с тем открывала новые возможности для развития этих областей знания.

Применение техники гравюры, тиражирование посредством нее сведений обеспечивало развитие географических наук, медицины, астрономии, ботаники, зоологии, всех тех областей знания, в которых важна была невербальная информация.

Многочисленные запросы человеческого общества в передаче изобразительной информации, раз- 


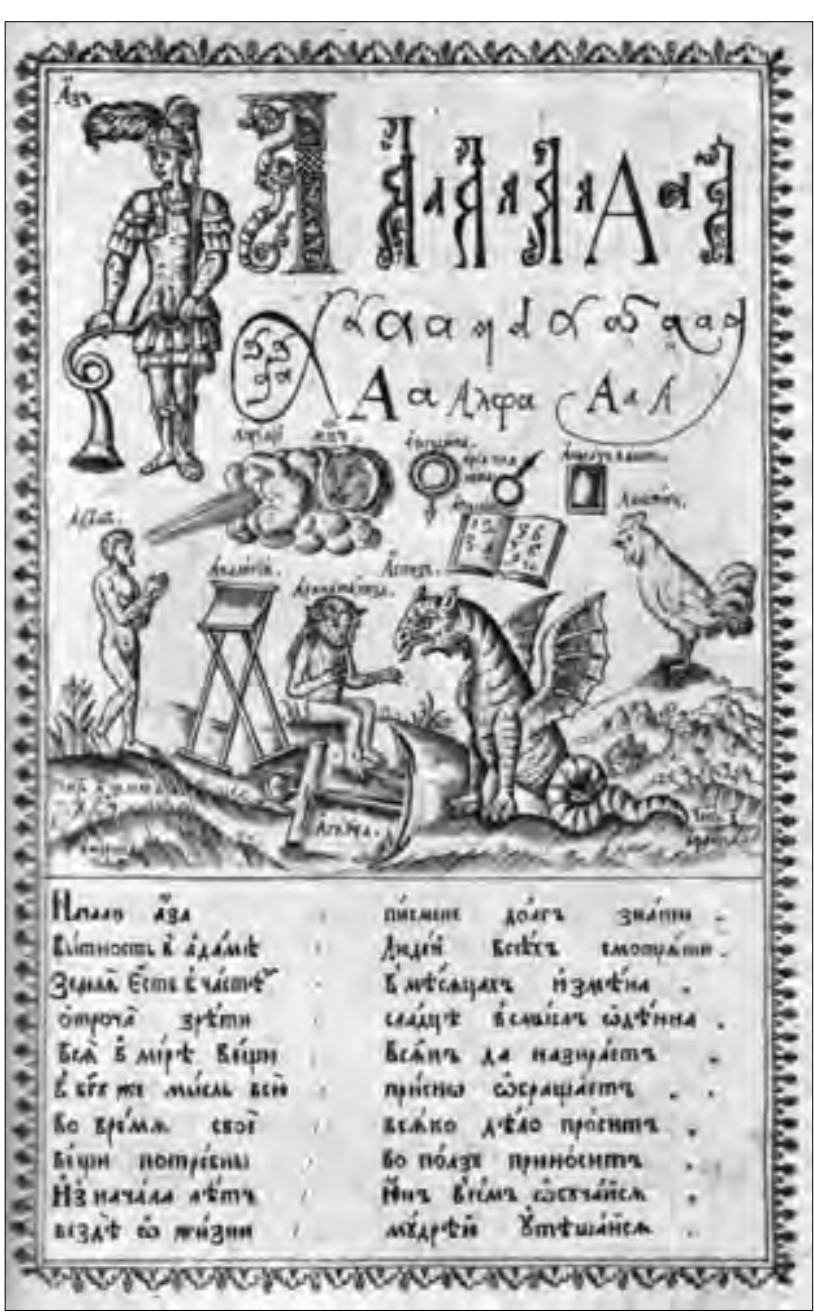

Цельногравированная книга.

«Букварь Кариона Истомина» с гравюрами Леонтия Бунина. 1694 г. Российская национальная библиотека

витие науки обеспечили возникновение и становление особого вида цельногравированной книги, где текст и изображение создавались посредством гравирования на одной печатной форме, медной или деревянной доске (пластине).

Появление цельногравированной книги было обусловлено и особенностями книжного дела эпохи: технической сложностью сочетания оттисков гравюры на металле (глубокой печати) и типографской (высокой) печатью в одном технологическом прогоне. В силу чего издания, требовавшие большого количества иллюстраций, разделялись на альбомную (цельногравированную) и печатную (типографскую) части. Такое взаимодействие двух техник книги сохранялось на протяжении всей эпохи Нового времени.

Цельногравированная книга нашла и самостоятельное применение в различных жанрах: детской, народной (лубочной) книге, географических, ботанических и других атласах, иконографических аль- бомах, календарях ${ }^{3}$ Цельногравированную форму наблюдаем и в учебных изданиях азбук и прописей, математических таблиц. Для выпуска некоторых официальных изданий, например орденских статутов, манифестов, также применялась техника гравюры. В цельногравированной форме издавалась значительная часть репертуара русской книги XVII-XIX вв., направленная на удовлетворение самых разнообразных запросов общества от высокой науки до ежедневных обыденных потребностей и развлечений.

В историографии гравюра рассматривалась обычно как вспомогательная техника в истории книги, а в большинстве случаев ее не отделяли от изобретения И. Гутенберга. Такой взгляд не отвечает реальному положению вещей, искажает пространство книжной культуры прошлого, не позволяет увидеть внутренние закономерности развития важнейшей области человеческой деятельности - книжного дела.

Основным и прогрессивным способом создания книги в эпоху Нового времени обычно считают типографскую печать и рассматривают ее как полностью доминирующую в книжной культуре эпохи. Действительно, типографская печать занимала значительное место в книжном репертуаре, а в некоторых его разделах преобладала полностью. Тем не менее, рассматривать типографскую книгу (высокой печати) как исключительное явление эпохи не совсем справедливо, поскольку по своей природе типографская печать не могла охватить всех запросов, потребностей времени. Кроме того, типографская печать, собственно типографская книга нередко представляла собой смешение различных техник печати, чаще всего высокой типографской печати и ксилографии, относящейся к высокой печати гравюры, обеспечивающей художественный образ книги, декор, художественные или функциональные иллюстрации.

Типографская печать соединялась и с металлографией (гравюрой на металле, глубокой печатью) в более сложном технологическом процессе, благодаря которому в книге возможно было передать естественно-научные или художественные иллюстрации, требующие более сложной пластической передачи изображения. Нередко типографская печать применялась для тиражирования вспомогательных текстов к альбомным изображениям, например, увражам с изображением фейерверков (гравюрам на меди), сопровождаемым брошюрами с текстами-комментариями, объяснениями, отпечатанными традиционным типографским способом. Типографская печать иногда сопровождалась текстами к географическим,

3 Заметим, что здесь мы иногда видим сугубо текстовые издания - применение техники гравюры для создания календаря связано со сложностью типографского набора, например, в связи с большим числом таблиц. 
анатомическим и другим атласам. Такие сочетания типографской печати и гравюры можно рассматривать как соединение, взаимодействие в одном издании (книге) основных техник книги эпохи.

Аналогичные взаимодействия, изначально определенные при создании книги, можно видеть и в некоторых жанрах рукописной книги XVIIXIX вв., например, в певческих рукописях, где каждый раздел открывался соответствующей гравированной рамкой-заставкой с изображением события, которому посвящалось следующее далее нотированное песнопение. Система гравированных украшений изначально создавала своеобразный макет, художественный образ книги, содержание которой восполнялось рукописным способом.

Взаимодействие различных техник в книге осуществлялось и на бытовом уровне, когда владелец сам определял или лично создавал необходимые с его точки зрения художественные украшения или заключал в один переплет исполненные в различных техниках издания. Так, в типографскую книгу попадали серии миниатюр или гравированных иллюстраций, изъятых из альбомов, например, для украшения Елизаветинской Библии из аугсбургских и нюрнбергских изданий И. Крауса и К. Вайгеля, а печатные «Страсти Христовы» украшали миниатюры, специально изготовленные или вырезанные из рукописи. Многочисленные лубочные издания использовались в качестве украшения рукописных книг, а печатные издания, пострадавшие, например, от влаги или механических повреждений, получившие утраты, восполняли рукописным способом и т. д. [45-48]. Все эти варианты изначально сознательных и на бытовом уровне смешений можно рассматривать как взаимодействие основных техник книги, обеспечивающих стабильное развитие и многообразие, вариативность книжной культуры эпохи.

Очевидно, что каждая техника обеспечивала особую форму книги, выполняла свои востребованные в обществе функции. Именно многообразие стоящих перед книгой задач, вели к взаимодействию различных техник и соединению различных форм книги в своеобразные гибридные формы (цельногравированная книга соединяется с рукописной и типографской, рукопись дополняла типографскую печать и т. п.). При этом мы имеем в виду не случайное иллюстрирование и дополнение книги иным техническим или художественным элементом, а наличие типологически устойчивых схем (макетов) дополнения одной техники (формы) книги другой или применение однотипного технического и художественного способа дополнения книги путем соединения разных техник книги и форм.

В такой ситуации развития книжной культуры невозможно говорить о прогрессивных формах книги и техниках книги. Можно лишь определить архаические техники как перешедшие из предшествующего

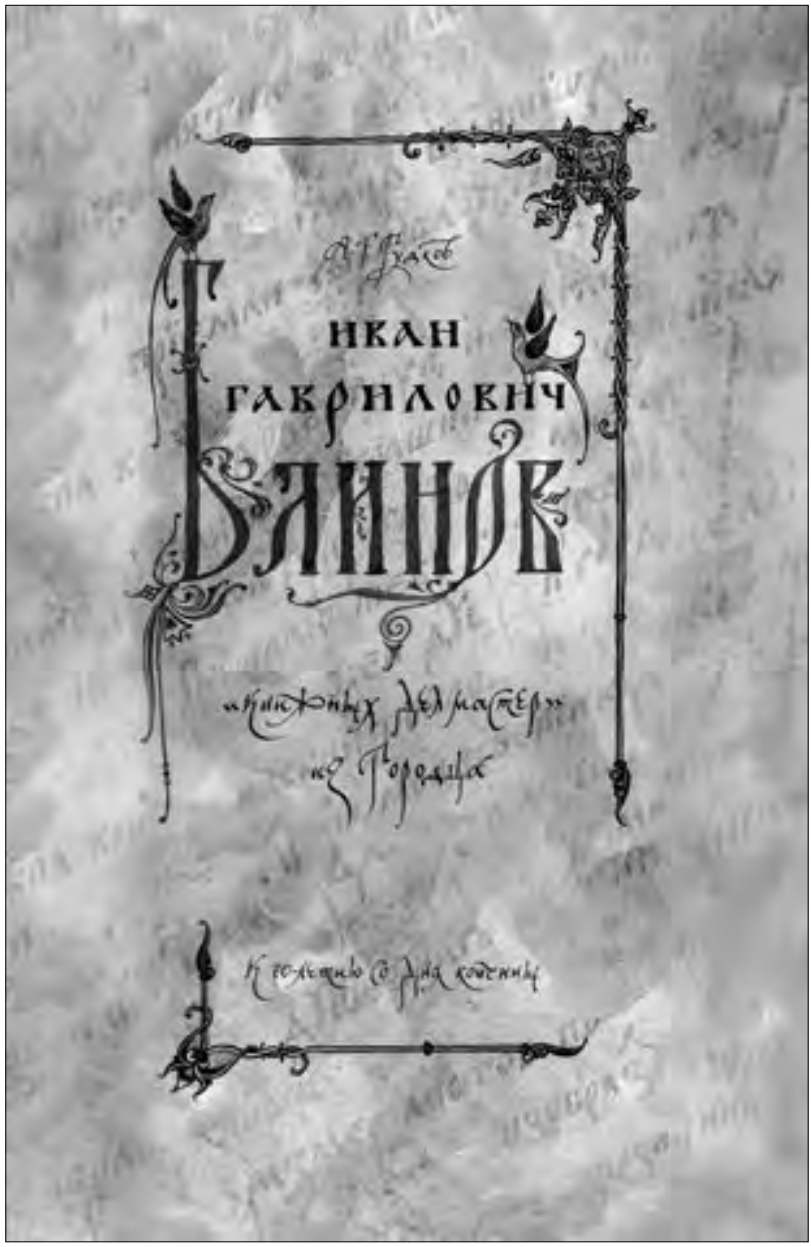

Рукописная книга продолжает существовать в качестве художественной техники. Обложка издания [50], 2015 г.

типа книжной культуры. При этом архаическая техника книги отнюдь не является чем-то изживаемым, незначительным. В определенный момент развития новых техник она переходит в иное качество, обеспечивает особые запросы общества, которые, впрочем, могли иметь место и в прошлом. Так, в середине второй половине XIX в. и даже в современную эпоху рукописная книга продолжает существовать, но в ином качестве не массовой, а исключительно художественной техники, предназначенной для создания книги как произведения искусства. В качестве иллюстрации этой мысли для XIX в. можно вспомнить рукописные книги, созданные академиком Ф.Г. Солнцевым, для ХХ в. - И.Г. Блиновым и др. [49; 50].

Изучая различные формы книги и их взаимодействие, можно понять внутренние закономерности, механизмы движения в книжной культуре, изменения в историческом пространстве книги, собственно «внешности» книги, ее формы, что и позволяет видеть историческое развитие книги как особого явления человеческой деятельности. В этом 
отношении модель ее исторического развития можно наблюдать через структуру книжной культуры, ее внутренних изменений.

Собственно структура книжной культуры Нового времени, пришедшая на смену рукописной эпохе, определялась основными техниками книги: архаической рукописной, обеспечивающей преемственность в развитии книги и новыми техниками гравюры и типографской печати, каждая из которых удовлетворяла определенные общественные запросы и обеспечивала существование новых форм книги.

Стабильное существование книжной культуры Нового времени продолжалось до 1830-1850-х гг., когда с развитием новых техник (литографии) и усовершенствованием техники гравюры (на стали, тоновая ксилография) началось постепенное вытеснение цельногравированной формы книги литографской, а с появлением фототехник окончательным изменением состава форм книги и структуры книжной культуры, исчезновением цельногравированной книги и различных гибридных форм (полугравированных). К 1890-м гг. складывается новый тип книжной культуры, просуществовавший уже до XXI в., когда с появлением компьютерных технологий начинается рождение ее нового типа.

Исчезновение цельногравированной книги и гравюры из книжного дела привело к их полному уходу в художественную культуру и чистое искусство, подобно тому, как ранее это произошло с рукописной книгой.

\section{Список источников}

1. Васильев В.И. История книжной культуры как научное направление отечественной истории и книговедения // Книга. Исследования и материалы. Москва, 2004. Сб. 82. С. 5-24.

2. Васильев В.И. Книга и книжная культура на переломных этапах истории России. Москва : Наука, 2005. 270 с.

3. Васильев В.И. Формирование понятия «книжная культура» и его развитие в современных исследованиях и публикациях // Книжная культура. Особенности становления и развития. Москва, 2008. С. $18-$ 25.

4. Васильев В.И. Современные тенденции в исследованиях по истории книжной культуры // Славянское книгопечатание и культура книги. Москва, 2009. С. 23-25.

5. Васильев В.И. Книга и книжная культура как составная часть культурно-исторического процесса: исследовательские тенденции и новые оценки // Книга - источник культуры: проблемы и методы их исследования. Минск, 2008. С. 381-399.

6. Тимофеева Ю.В. Книжная культура: дефиниции понятия // Философия образования. 2011. № 5. С. $268-$ 275.

7. Казакова Г.М. О содержании и качественных границах понятия книжной культуры // Вестник Челябин- ской государственной академии культуры и искусства. 2012. № 2. С.71-74.

8. Крылова Е.В. Книжная культура сегодня: подходы к определению и содержанию понятия // Вестник Русской христианской гуманитарной академии. 2012. Т.13, вып. 3. С. $185-191$.

9. Сидоров А.А. Искусство книги. Москва : Дом печати, $1922.100 \mathrm{c}$.

10. Сидоров А.А. Книга как объект изучения и художественные элементы книги // Книга в России. Ч. І. Русская книга от начала письменности до 1800 года. Москва, 1924. С. 9-32.

11. Афанасъева Н. Полиграфическая секция и Библиологический отдел ГАХН // Вопросы искусствознания. 1997. [Вып.] XI (2/97). С. 310-317.

12. Берков П.Н. История советского библиофильства. Москва : Книга, 1971. С. 88-126.

13. Саввичева Н.М. История Русского общества друзей книги (РОДК. 1920-1929 гг.) : автореф. дис. ... канд. ист. наук. Москва, 1993. 24 с.

14. Гулина Т.И. Книги гражданской печати 1708-1800 гг. из собрания Ярославского музея-заповедника : каталог. Рыбинск, 2003. 671 с.

15. Сводный каталог книг гражданской печати XVIII 1-й четверти XIX века в собраниях Урала. В 2 т. Т. 1. А - М / Е.П. Пирогова, С.А. Белобородов ; под общ. ред. Е.П. Пироговой. Екатеринбург : Сократ, 2005. 525 ; Т. 2. Н - Я / Е.П. Пирогова, С.А. Белобородов, М.В. Исаева, М.Б. Бариева. Екатеринбург : Сократ, 2007. 581 c.

16. Кириллические издания XVII века в собрании Переславского музея-заповедника : каталог / под ред. И.В. Поздеевой. Переславль-Залесский : [б. и.] ; Москва : [б. и.], 2012. 294 с.

17. Кириллические издания XVIII века в хранилищах Пермского края : каталог / под ред. И.В. Поздеевой. Пермь : Пушка, 2008. 797 с.

18. Мишина Е.А. Азбуки-свитки XVII-XVIII веков // От Средневековья к Новому времени : сборник статей в честь Ольги Андреевны Белобровой. Москва, 2006. C. 419-431.

19. Романова В.Л. Рукописная книга и готическое письмо во Франции в XIII - XIV вв. По материалам собрания рукописных книг Государственной Публичной библиотеки им. М.Е. Салтыкова-Щедрина. Москва : Наука, 1975. С. 44-81.

20. Хромов О.Р. Гравюра в рукописной книге XVIXIX вв. Проблемы описания и идентификации // 450 лет «Апостолу» Ивана Федорова. История раннего книгопечатания в России (памятники, источники, традиции изучения). Москва, 2015. С. 336-346.

21. Хромов O.P. Русская лубочная книга XVII-XIX веков. Москва : Памятники исторической мысли, 1998. С. $101-103$.

22. Семячко С.А. Об автографах Диомида Серкова и сборнике «Крины сельные» // Труды отдела древнерусской литературы Института русской литературы 
(Пушкинского Дома) Российской академии наук. Санкт-Петербург, 2003. Т. 54. С. 613-622.

23. Семячко С.А. Автограф Диомида Серкова в Библиотеке Академии наук // Материалы и сообщения по фондам рукописного отдела Библиотеки Российской академии наук. Санкт-Петербург, 2014. C. $131-140$.

24. Хромов О.Р. Гравюра на русском Севере в последней трети XVII столетия. Мастерские Антониево-Сийского и Соловецкого монастырей // Первая международная научная конференция «Духовное и историко-культурное наследие Соловецкого монастыря» : сборник научных статей и докладов. Соловки, 2011. C. 138-145.

25. Хромов О.Р. Об оформлении нескольких неизвестных рукописей книжного мастера конца XVII века Диомида Яковлева сына Серкова // Искусство книги и гравюра в художественной культуре. Москва, 2014. С. $168-172$.

26. Хромов О.Р. Букварь Кариона Истомина с рукописными дополнениями Диомида Яковлева сына Серкова как памятник русской книжности XVII века // Отечественная и зарубежная педагогика. 2015. № 1 (22). C. $7-17$.

27. Крутова М.С., Хромов О.Р. Сборник литературно-публицистический конца XVII - начала XVIII в. с неизвестной гравюрой Леонтия Бунина (Новое поступление в НИОР РГБ) // Записки отдела рукописей Российской государственной библиотеки. Москва, 2012. Вып. 54. С. 302-307.

28. Хромов О.Р. Цельногравированная книга и гравюра в русских рукописях XVI-XIX веков : каталог коллекции отдела письменных источников Ярославского государственного историко-архитектурного и художественного музея-заповедника. Москва : Арт-Родник, 2013. 439 c.

29. Хромов О.Р. Русская рукописная книга с гравюрами в контексте общеевропейской книжной культуры XVII-XVIII вв. (специфика и общие тенденции оформления жанра) // Берковские чтения. Книжная культура в контексте международных контактов : материалы Международной научной конференции (25-26 мая 2011 г.). Минск, 2011. С. $375-379$.

30. Хромов О.Р. Рукописная книга с гравюрами - новый жанр в искусстве русской книги позднего Средневековья и Нового времени // Библиотековедение. 2012. № 3. С. 54-61.

31. Хромов О.Р. Гравюра и книга. Об одной тенденции в эволюции художественной формы книги и изменении типа книжной культуры // Берковские чтения. Материалы Международной научной конференции «Книжная культура в контексте международных контактов». Минск, 2013. С. 418-422.

32. Мишина Е.А. Святцы Антониево-Сийского монастыря и их предполагаемый автор // Филевские чтения. Москва, 1994. Вып. V. С. 3-14.
33. Хромов О.Р. Цельногравированный Синодик в русском обиходе XVIII-XIX веков // Православие и народная культура. Москва, 1996. Кн. 6. С. 23-59.

34. Белоброва О.А. Гравированные «Страсти Христовы», с виршами, в рукописных сборниках XVIII в. из Древлехранилища Пушкинского Дома // О.А. Белоброва. Очерки русской художественной культуры XVIХХ веков. Москва, 2005. С. 396 - 406.

35. Хромов О.Р. Рукопись «Страсти Христовы» 1730-х гг. с гравюрами XVII, XVIII вв. (Новое поступление в НИОР РГБ) // Румянцевские чтения : материалы Международной научной конференции (15-16 апреля 2008 г.). Москва, 2008. С. 365-370.

36. Братчикова Е.К. «Страсти Христовы» в лицевой рукописной традиции мастеров-старообрядцев. // Материалы и сообщения по фондам отдела рукописей Библиотеки Российской академии наук. Санкт-Петербург, 2006. С. $74-80$.

37. Грибов Ю.А. Рукописный синодик с ксилографическими иллюстрациями - памятник русской книжности начала XVIII в. // Забелинские научные чтения - Год 1999-й. Исторический музей - энциклопедия отечественной истории и культуры. Труды Государственного исторического музея. Москва, 1999. Вып. 121. C. $75-102$.

38. Хромов О.Р. Об одном неизвестном листовом (летучем) издании Московского печатного двора // Румянцевские чтения - 2015 : материалы Международной научной конференции (14-15 апреля 2015 г.). Москва, 2015. Ч. 2. С. 207- 209.

39. Винокурова Э.П. К вопросу о «дониконовской» ориентации старообрядцев в изобразительном искусстве // Традиционная духовная и материальная культура русских старообрядческих поселений в странах Европы, Азии и Америки. Новосибирск, 1992. С. 64-73.

40. Винокурова Э.П. К вопросу о генезисе поморского орнамента // Литература Древней Руси. Источниковедение. Ленинград, 1988. С. 259-289.

41. Мишина Е.А. Гравированные рамки-заставки XVII века // Ростовский Архиерейский дом и русская художественная культура второй половины XVII века. Ростов, 2006. С. 270-279.

42. Плигузов А.И. К изучению орнаментики ранних рукописей Выга // Рукописная традиция XVIXIX вв. на Востоке России. Новосибирск, 1983. C. $82-101$.

43. Хромов О.P. Гравированные заставки-рамки в рукописных книгах XVII-XIX вв. (Принципы описания и составления каталога-определителя) // Записки отдела рукописей Российской государственной библиотеки. Москва, 2012. Вып. 54. С. 85-102.

44. Хромов О.Р. Гравюра в истории книги // Обсерватория культуры. 2016. Т. 13, № 4. С. 506-511.

45. Горфункель А.Х. Иллюстрированный экземпляр Елизаветинской Библии в Бостонской публичной библиотеке // Книга. Исследования и материалы. Москва, 1996. Сб. 72. С. 207-211. 
46. Воробъева Е.В., Хромов О.Р. Редкие экземпляры Елизаветинской Библии (по фондам Государственной публичной исторической библиотеки России) // Библиотековедение. 2002. № 4. С. 58-64.

47. Хромов О.Р. Неизвестные гравюры XVII - начала XVIII в. в рукописных книгах из собрания П.А. Овчинникова в НИОР РГБ // Румянцевские чтения 2013 : материалы Международной научной конференции (16-17 апреля 2013 г.). Ч. 2. Москва, 2013. С. $286-292$.
48. Хромов О.P. Ранняя русская ксилография XVIIXVIII вв. и оформление сборника № 4717 из Музейного собрания НИОР РГБ // Румянцевские чтения - 2009 : материалы Международной научной конференции (21-23 апреля 2009 г.). Ч. 1. Москва, 2009. С. 262-267.

49. Аксенова Г.В. Русский стиль. Гений Федора Солнцева. Москва : Слово/Slovo, 2009. 392 с.

50. Гудков А.Г. Иван Гаврилович Блинов: «книжных дел мастер» из Городца: К 70-летию со дня кончины. Коломна : Лига, 2015. 224 с.

\section{THE STRUCTURE OF THE MODERN PERIOD BOOK CULTURE AND THE MECHANISMS OF BOOK HISTORICAL DEVELOPMENT}

\section{OLEG R. KHROMOV}

V.I. Surikov Moscow State Academic Art Institute at the Russian Academy of Arts, 30, Tovarishchesky Lane, Moscow, 109004, Russia

Russian State Library, 3/5, Vozdvizhenka St., Moscow, 119019, Russia

E-mail: oleghrom@gmail.com

\begin{abstract}
The article examines the form of book and the book culture of the Modern Period. The author defines that the form of book is in direct correlation to the technology and artistic image of the book, and the book culture is considered as a combination of different forms of books in their interaction. The author reconstructs the Modern Period book culture on the basis of main book techniques - manuscript, engraving, printing. These techniques define the existence of three basic forms of the Modern Period book - hand-written book, engraved book, printed book. According to the author's opinion, each of the forms is determined by specific social needs and demands of the historical period. In addition to the three basic forms, the book culture of the Modern Period includes some hybrid book forms, which appeared as a result of the interaction between different book techniques - e.g. "engraved and hand-written", "engraved and printed", etc. Their occurrence is caused by the needs of society and the technical capabilities of that time. The ratio of the book techniques in a certain historical period depends on the level of development of the book distribution system.

According to this approach, the history of books is considered as a consecutive change of book culture types, which happens due to the emergence of new techniques of the book. The emergence of new book techniques gradually destabilizes the stable (traditional) type of book culture - because of the appearance of new bookforms in its
\end{abstract}

interior - and thus contributes to the emergence of a new type of book culture and a new period in the development and history of books. Such a model of book development is shown for the first time in this article.

Key words: bibliology, history of engraving, engraving, history of books, book art, hand-written book, engraved book, printed book, typography.

Citation: Khromov O.R. The Structure of the Modern Period Book Culture and the Mechanisms of Book Historical Development, Observatory of Culture, 2017, vol. 14, no. 3, pp. 344-357.

\section{References}

1. Vasilyev V.I. Istoriya knizhnoi kul'tury kak nauchnoe napravlenie otechestvennoi istorii i knigovedeniya [The History of Book Culture as a Scientific Branch of National History and Bibliology], Kniga. Issledovaniya i mateia$l y$ [The Book. Researches and Materials]. Moscow, 2004, coll. 82, pp. 5-24.

2. Vasilyev V.I. Kniga i knizhnaya kul'tura na perelomnykh etapakh istorii Rossii [The Book and Book Culture at the Critical Stages of Russian History]. Moscow, Nauka Publ., 2005, $270 \mathrm{p}$.

3. Vasilyev V.I. Formirovanie ponyatiya "knizhnaya kul'tura" i ego razvitie $v$ sovremennykh issledovaniyakh i publikatsiyakh [Formation of the Concept of "Book Culture" and its Development in Modern Studies and Publications], Knizhnaya kul'tura. Osobennosti stanovleniya i razvitiya [Book Culture. The Features of Formation and Development]. Moscow, 2008, pp. 18-25.

4. Vasilyev V.I. Sovremennye tendentsii v issledovaniyakh po istorii knizhnoi kul'tury [Current Trends in the Researches on the History of Book Culture], Slavyanskoe knigopechatanie $i$ kul'tura knigi [The Slavonic Book-Printing and Book Culture]. Moscow, 2009, pp. 23-25.

5. Vasilyev V.I. Kniga i knizhnaya kul'tura kak sostavnaya chast' kul'turno-istoricheskogo protsessa: issledovatel'skie tendentsii i novye otsenki [The Book and Book Culture as an Integral Part of the Cultural-Historical Process: the Research Trends and New Estimates], Kniga - istochnik kul'tury: problemy i metody ikh issledovaniya [The Book Is a Source of Culture: the Problems 
and Methods of their Research]. Minsk, 2008, pp. 381399.

6. Timofeeva Yu.V. Knizhnaya kul'tura: definitsii ponyatiya [The Book Culture: Definitions of the Notion], Filosofiya obrazovaniya [Philosophy of Education], 2011, no. 5, pp. 268-275.

7. Kazakova G.M. O soderzhanii i kachestvennykh granitsakh ponyatiya knizhnoi kul'tury [About Content and Quality Limits of the Notion of "Book Culture"], Vestnik Chelyabinskoi gosudarstvennoi akademii kul'tury i iskusst$v a$ [Herald of the Chelyabinsk State Academy of Culture and Arts], 2012, no. 2, pp. 71-74.

8. Krylova E.V. Knizhnaya kul'tura segodnya: podkhody k opredeleniyu i soderzhaniyu ponyatiya [The Book Culture Today: Approaches to Definition and Contents of the Notion], Vestnik Russkoi khristianskoi gumanitarnoi akademii [Herald of the Russian Christian Academy for $\mathrm{Hu}-$ manities], 2012, vol. 13, issue 3, pp. 185-191.

9. Sidorov A.A. Iskusstvo knigi [The Art of Book]. Moscow, Dom Pechati Publ., 1922, 100 p.

10. Sidorov A.A. Kniga kak ob"ekt izucheniya i khudozhestvennye elementy knigi [The Book as an Object of Study and the Artistic Elements of Book], Kniga v Rossii. Ch. I. Russkaya kniga ot nachala pis'mennosti do 1800 goda [The Book in Russia. Part I. The Russian Book from the Beginning of Writing to 1800]. Moscow, 1924, pp. 9-32.

11. Afanasyeva N. Poligraficheskaya sektsiya i Bibliologicheskii otdel GAKhN [The Printing Section and Bibliological Department of the State Academy of Artistic Sciences], Voprosy iskusstvoznaniya [Questions of Art Studies], 1997, issue XI (2/97), pp. 310-317.

12. Berkov P.N. Istoriya sovetskogo bibliofil'stva [The History of Soviet Bibliophilia]. Moscow, Kniga Publ., 1971, pp. $88-126$.

13. Savvicheva N.M. Istoriya Russkogo obshchestva druzei knigi (RODK. 1920 - 1929 gg.) [The History of the Russian Society of Friends of Books (RODK. 1920 - 1929)], Cand. hist. sci. diss. Abstr. Moskva, 1993, 24 p.

14. Gulina T.I. Knigi grazhdanskoi pechati 1708-1800 gg. iz sobraniya Yaroslavskogo muzeya-zapovednika: katalog [The Civil Type Books of 1708-1800 from the Collection of the Yaroslavl Museum-Preserve: the Catalogue]. Rybinsk, 2003, 671 p.

15. Pirogova E.P. (ed.) Svodnyi katalog knig grazhdanskoi pechati XVIII - 1-i chetverti XIX veka v sobraniyakh Urala [The Union Catalogue of Civil Type Books of the 18th 1st Quarter of the 19th Century in the Urals Collections], vol. 1. Ekaterinburg, Sokrat Publ., 2005, 525 p.; vol. 2. Ekaterinburg, Sokrat Publ., 2007, 581 p.

16. Pozdeeva I.V. (ed.) Kirillicheskie izdaniya XVII veka v sobranii Pereslavskogo muzeya-zapovednika: katalog [The Cyrillic Publications of the 17th Century in the Collection of the Pereslavl Museum: the Catalogue]. PereslavlZalessky, Moscow, 2012, 294 p.

17. Pozdeeva I.V. (ed.) Kirillicheskie izdaniya XVIII vekav khranilishchakh Permskogo kraya: katalog [The Cyrillic Publications of the 18th Century in the Collections of the
Perm Region: the Catalogue]. Perm, Pushka Publ., 2008, $797 \mathrm{p}$.

18. Mishina E.A. Azbuki-svitki XVII-XVIII vekov [The Alphabet-Scrolls of the 17 th -18 th Centuries], $O t$ Srednevekov'ya $k$ Novomu vremeni: sbornik statei $v$ chest' Ol'gi Andreevny Belobrovoi [From Middle Ages to Early Modern Time: the Collection of Papers in Honor of Olga Andreyevna Belobrova]. Moscow, 2006, pp. 419-431.

19. Romanova V.L. Rukopisnaya kniga i goticheskoe pis'mo vo Frantsii v XIII - XIV vv. Po materialam sobraniya rukopisnykh knig Gosudarstvennoi Publichnoi biblioteki im. M.E. Saltykova-Shchedrina [The Manuscripts and Gothic Letters in France in the 13th - 14th Centuries. On the Materials of the Collection of Manuscripts of the M.E. Saltykov-Shchedrin State Public Library]. Moscow, Nauka Publ., 1975, pp. 44-81.

20. Khromov O.R. Gravyura v rukopisnoi knige XVI-XIX vv. Problemy opisaniya i identifikatsii [Engravings in the Manuscript Books of the 16th-19th Centuries. The Problems of Description and Identification], 450 let "Apostolu" Ivana Fedorova. Istoriya rannego knigopechataniya $v$ Rossii (pamyatniki, istochniki, traditsii izucheniya) [450th Anniversary of the Apostle by Ivan Fyodorov. The History of Early Printing in Russia (Monuments, Sources, Traditions of Study)]. Moscow, 2015, pp. 336-346.

21. Khromov O.R. Russkaya lubochnaya kniga XVII-XIX vekov [The Russian Woodcut Book of the 17th-19th Centuries]. Moscow, Pamyatniki Istoricheskoi Mysli Publ., 1998, pp. 101-103.

22. Semyachko S.A. Ob avtografakh Diomida Serkova i sbornike "Kriny sel'nye" [About the Autographs of Diomid Serkov and the Book "Kriny sel'nye"], Trudy otdela drevnerusskoi literatury Instituta russkoi literatury (Pushkinskogo Doma) Rossiiskoi akademii nauk [Proceedings of the Department of Old Russian Literature of the Institute of Russian Literature (Pushkin House) of the Russian Academy of Sciences]. St. Petersburg, 2003, vol. 54, pp. 613-622.

23. Semyachko S.A. Avtograf Diomida Serkova v Biblioteke Akademii nauk [The Autograph of Diomid Serkov in the Library of Academy of Sciences], Materialy $i$ soobshcheniya po fondam rukopisnogo otdela Biblioteki Rossiiskoi akademii nauk [Materials and Reports on the Holdings of the Manuscript Department of the Library of Russian Academy of Sciences]. St. Petersburg, 2014, pp. $131-140$.

24. Khromov O.R. Gravyura na russkom Severe v poslednei treti XVII stoletiya. Masterskie Antonievo-Siiskogo i Solovetskogo monastyrei [Engraving in the Russian North in the Last Third of the 17th Century. The Workshops of Antonievo-Siysky and Solovetsky Monasteries], Pervaya mezhdunarodnaya nauchnaya konferentsiya "Dukhovnoe $i$ istoriko-kul'turnoe nasledie Solovetskogo monastyrya": sbornik nauchnykh statei i dokladov [Proceedings of the First International Scientific Conference "Spiritual and Historical-Cultural Heritage of the Solovetsky Monastery”]. Solovki, 2011, pp. 138-145. 
25. Khromov O.R. Ob oformlenii neskol'kikh neizvestnykh rukopisei knizhnogo mastera kontsa XVII veka Diomida Yakovleva syna Serkova [About the Design of Several Unknown Manuscripts of the Book Master of the Late 17th Century Diomid Yakovlev, Son of Serkov], Iskusstvo knigi i gravyura $v$ khudozhestvennoi kul'ture [The Art of Book and Engraving in the Artistic Culture]. Moscow, 2014, pp. 168-172.

26. Khromov O.R. Bukvar' Kariona Istomina s rukopisnymi dopolneniyami Diomida Yakovleva syna Serkova kak pamyatnik russkoi knizhnosti XVII veka [ABC-Book by Karion Istomin with Handwritten Additions of Diomid Yakovlev, Serkov's Son, as a Monument of Russian Bookishness of 17th Century], Otechestvennaya i zarubezhnaya pedagogika [National and Foreign Pedagogy], 2015, no. 1 (22), pp. 7- 17.

27. Krutova M.S., Khromov O.R. Sbornik literaturno-publitsisticheskii kontsa XVII - nachala XVIII vv. s neizvestnoi gravyuroi Leontiya Bunina (Novoe postuplenie $\mathrm{V}$ NIOR RGB) [Literary and Journalistic Collection of the Late 17th - Early 18th Centuries with an Unknown Engraving of Leonty Bunin (A New Acquisition of the Manuscript Department of the Russian State Library)], Zapiski otdela rukopisei Rossiiskoi gosudarstvennoi biblioteki [Notes of the Manuscript Department of the Russian State Library]. Moscow, 2012, issue 54, pp. 302-307.

28. Khromov O.R. Tsel'nogravirovannaya kniga i gravyura $v$ russkikh rukopisyakh XVI-XIX vekov: katalog kollektsii otdela pis'mennykh istochnikov Yaroslavskogo gosudarstvennogo istoriko-arkhitekturnogo i khudozhestvennogo muzeya-zapovednika [The All-Engraved Books and Engravings in Russian Manuscripts of the 16th-19th Centuries: the Catalogue of the Department of Written Sources' Collection of the Yaroslavl State Historical-Architectural and Artistic Museum-Reserve]. Moscow, Art-Rodnik Publ., 2013, 439 p.

29. Khromov O.R. Russkaya rukopisnaya kniga s gravyurami v kontekste obshcheevropeiskoi knizhnoi kul'tury XVIIXVIII vv. (spetsifika i obshchie tendentsii oformleniya zhanra) [The Russian Manuscript Book with Engravings in the Context of the European Book Culture of the 17th-18th Centuries (the Genre's Specifics and General Trends)], Berkovskie chteniya. Knizhnaya kul'tura $v$ kontekste mezhdunarodnykh kontaktov: materialy mezhdunarodnoi nauchnoi konferentsii (25-26 maya 2011 g.) [The Berkov Readings. Book Culture in the Context of International Contacts: Proceedings of the International Scientific Conference (May 25-26, 2011)]. Minsk, 2011, pp. 375-379.

30. Khromov O.R. Rukopisnaya kniga s gravyurami - novyi zhanr v iskusstve russkoi knigi pozdnego Srednevekov'ya i Novogo vremeni [Manuscript Book with Engravings a New Genre in the Russian Book Art of the Late Middle Ages and Modern Times], Bibliotekovedenie [Library and Information Science], 2012, no. 3, pp. 54-61.

31. Khromov O.R. Gravyura i kniga. Ob odnoi tendentsii v evolyutsii khudozhestvennoi formy knigi i izmenenii tipa knizhnoi kul'tury [The Engraving and the Book. About One Trend in the Evolution of the Artistic Form of Book and a Change in the Type of Book Culture], Berkovskie chteniya. Materialy Mezhdunarodnoi nauchnoi konferentsi "Knizhnaya kul'tura v kontekste mezhdunarodnykh kontaktov" [The Berkov Readings. Proceedings of the International Scientific Conference "Book Culture in the Context of International Contacts”]. Minsk, 2013, pp. 418-422.

32. Mishina E.A. Svyattsy Antonievo-Siiskogo monastyrya i ikh predpolagaemyi avtor [The Calendar of AntonievoSiysky Monastery and its Presumed Author], Filevskie chteniya [The Fili Readings]. Moscow, 1994, issue V, pp. $3-14$.

33. Khromov O.R. Tsel'nogravirovannyi Sinodik v russkom obikhode XVIII-XIX vekov [The All-Engraved Synodicon in the Russian Everyday Life of the 18th-19th Centuries], Pravoslavie i narodnaya kul'tura [Orthodoxy and the Popular Culture]. Moscow, 1996, book 6, pp. 23-59.

34. Belobrova O.A. Gravirovannye "Strasti Khristovy", s virshami, v rukopisnykh sbornikakh XVIII v. iz Drevlekhranilishcha Pushkinskogo Doma [Engraved "The Passion of the Christ”, with Verses, in the Manuscript Collections of the 18th Century from the Archive of the Pushkin House], O.A. Belobrova. Ocherki russkoi khudozhestvennoi kul'tury $X V I-X X$ vekov [O.A.Belobrova. The Essays on Russian Culture of the 16th-20th Centuries]. Moscow, 2005, pp. $396-406$.

35. Khromov O.R. Rukopis' "Strasti Khristovy” 1730-kh gg. s gravyurami XVII, XVIII vv. (Novoe postuplenie v NIOR RGB) [“The Passion of the Christ” Manuscript of the 1730s, with Engravings of the 17th, 18th Centuries (A New Acquisition of the Manuscript Department of the Russian State Library)], Rumyantsevskie chteniya: materialy Mezhdunarodnoi nauchnoi konferentsii (15-16 aprelya 2008) [The Rumyantsev Readings: Proceedings of the International Scientific Conference (April 15-16, 2008)]. Moscow, 2008, pp. 365-370.

36. Bratchikova E.K. "Strasti Khristovy" v litsevoi rukopisnoi traditsii masterov-staroobryadtsev ["The Passion of the Christ" in the Personal Manuscript Tradition of Old Believing Masters], Materialy i soobshcheniya po fondam otdela rukopisei Biblioteki Rossiiskoi akademii nauk [Materials and Reports on the Holdings of the Manuscript Department of the Library of Russian Academy of Sciences]. St. Petersburg, 2006, pp. $74-80$.

37. Gribov Yu.A. Rukopisnyi sinodik s ksilograficheskimi illyustratsiyami - pamyatnik russkoi knizhnosti nachala XVIII v. [The Handwritten Commemoration Book with Xylographic Illustrations - the Monument of Russian Literature of the Beginning of the 18th Century], Zabelinskie nauchnye chteniya - God 1999-i. Istoricheskii muzei entsiklopediya otechestvennoi istorii i kul'tury. Trudy Gosudarstvennogo istoricheskogo muzeya [The Zabelin Scientific Readings - Year 1999. Historical Museum - the Encyclopedia of Russian History and Culture. Proceedings of the State Historical Museum]. Moscow, 1999, issue 121, pp. $75-102$. 
38. Khromov O.R. Ob odnom neizvestnom listovom (letuchem) izdanii Moskovskogo pechatnogo dvora [About an Unknown Sheet (Volatile) Publication of the Moscow Print Yard], Rumyantsevskie chteniya - 2015: materialy Mezhdunarodnoi nauchnoi konferentsii 14-15 aprelya 2015 [The Rumyantsev Readings - 2015: Proceedings of the International Scientific Conference (April 14-15, 2015)]. Moscow, 2015, part 2, pp. 207- 209.

39. Vinokurova E.P. K voprosu o "donikonovskoi" orientatsii staroobryadtsev v izobrazitel'nom iskusstve [To the Question of "Pre-Nikon" Orientation of the Old Believers in Visual Arts], Traditsionnaya dukhovnaya i material'naya kul'tura russkikh staroobryadcheskikh poselenii v stranakh Evropy, Azii i Ameriki [The Traditional Spiritual and Material Culture of Russian Old Believer Communities in Europe, Asia and America]. Novosibirsk, 1992, pp. 64-73.

40. Vinokurova E.P. K voprosu o genezise pomorskogo ornamenta [To the Question of Genesis of the Pomeranian Ornament], Literatura Drevnei Rusi. Istochnikovedenie [The Literature of Ancient Russia. Source Studies]. Leningrad, 1988, pp. 259-289.

41. Mishina E.A. Gravirovannye ramki-zastavki XVII veka [The Engraved Frames-Headpieces of the 17th Century], Rostovskii Arkhiereiskii dom i russkaya khudozhestvennaya kul'tura vtoroi poloviny XVII veka [The Rostov Archbishop House and Russian Artistic Culture of the Second Half of the 17th Century]. Rostov, 2006, pp. 270-279.

42. Pliguzov A.I. K izucheniyu ornamentiki rannikh rukopisei Vyga [To the Study of Ornamentation of the Early Vyg Manuscripts], Rukopisnaya traditsiya XVI-XIX vv. na Vostoke Rossii [The Manuscript Tradition of the 16th19th Centuries in the East of Russia]. Novosibirsk, 1983, pp. 82-101.

43. Khromov O.R. Gravirovannye zastavki-ramki v rukopisnykh knigakh XVII-XIX vv. (Printsipy opisaniya i sostavleniya kataloga-opredelitelya) [The Engraved Headpieces-Frames in the Handwritten Books of the 17th-19th Centuries (The Principles of Description and Compilation of the Auxiliary Catalogue)], Zapiski otdela rukopisei Rossiiskoi gosudarstvennoi biblioteki [Notes of the Manuscript Department of the Russian State Library]. Moscow, 2012, issue 54, pp. 85-102.
44. Khromov O.R. Gravyura v istorii knigi [Engraving in the History of Book], Observatoriya kul'tury [Observatory of Culture], 2016, vol. 13, no.4, pp. 506-511.

45. Gorfunkel A.Kh. Illyustrirovannyi ekzemplyar Elizavetinskoi Biblii v Bostonskoi publichnoi biblioteke [Illustrated Copy of the Elizabethan Bible in the Boston Public Library], Kniga. Issledovaniya i materialy [The Book. Researches and Materials]. Moscow, 1996, coll. 72, pp. 207-211.

46. Vorobyova E.V., Khromov O.R. Redkie ekzemplyary Elizavetinskoi Biblii (po fondam Gosudarstvennoi publichnoi istoricheskoi biblioteki Rossii) [Rare Copies of the Elizabethan Bible (in the Collection of the State Public Historical Library of Russia)], Bibliotekovedenie [Library and Information Science], 2002, no. 4, pp. 58-64.

47. Khromov O.R. Neizvestnye gravyury XVII - nachala XVIII v. v rukopisnykh knigakh iz sobraniya P.A. Ovchinnikova v NIOR RGB [The Unknown Engravings of the 17th - Beginning of the 18th Century in the Manuscripts from the Collection of P.A. Ovchinnikov in the Manuscript Department of the Russian State Library], Rumyantsevskie chteniya - 2013. Materialy Mezhdunarodnoi nauchnoi konferentsii (16-17 aprelya 2013) [The Rumyantsev Readings. Proceedings of the International Scientific Conference (April 16-17, 2013)], part 2. Moscow, 2013, pp. 286-292.

48. Khromov O.R. Rannyaya russkaya ksilografiya XVIIXVIII vv. i oformlenie sbornika № 4717 iz Muzeinogo sobraniya NIOR RGB [The Early Russian Woodcuts of the 17th-18th Centuries and the Design of the Collection No. 4717 from the Museum Collection of the Manuscript Department of the Russian State Library], Rumyantsevskie chteniya - 2009: materialy Mezhdunarodnoi nauchnoi konferentsii (21-23 aprelya 2009 g.) [The Rumyantsev Readings - 2009. Proceedings of the International Scientific Conference (April 21-23, 2009)], part 1. Moscow, 2009, pp. 262-267.

49. Aksenova G.V. Russkii stil’. Genii Fedora Solntseva [Russian Style. The Genius of Fyodor Solntsev]. Moscow, Slovo/Slovo Publ., 2009, 392 p.

50. Gudkov A.G. Ivan Gavrilovich Blinov: "knizhnykh del master" iz Gorodtsa: K 70-letiyu so dnya konchiny [Ivan Gavrilovich Blinov: the "Book Master” from Gorodets: To the 70th Anniversary of his Death]. Kolomna, Liga Publ., 2015, 224 p. 